DOI 10.37882/2223-2982.2021.06.22

\title{
КОНТРОЛЬНЫЕ ВОПРОСЫ К ТЕКСТАМ ДИСТАНЦИОННОГО ОБУЧЕНИЯ
}

\section{CONTROL QUESTIONS FOR DISTANCE LEARNING TEXTS}

\section{Yu. Kalugin \\ A. Prokhorov}

Summary: The article defines the role of control questions for educational texts that are used in distance and distance education. It contains a brief description of mental operations and their participation in the formation of the quantitative and qualitative volume of knowledge, skills and abilities of the student. Some recommendations are given for the formation of a series of control questions for the educational text, designed to train certain mental operations.

Keywords: educational text, reproductive actions, productive actions, mental operations.

\author{
Калугин Юрий Евгеньевич \\ К.п.н., дочент, ФГАОУ ВО «Южно-Уральский \\ государственный университет (национальный \\ исследовательский университет)» \\ Прохоров Александр Владимирович \\ К.т.н., дочент, ФГАОУВО «Южно-Уральский \\ государственный университет (национальный \\ исследовательский университет)» \\ prokhorovav@susu.ru
}

Аннотация: Статья определяет роль контрольных вопросов к учебным текстам, которые используются при дистанционном и заочном образовании. Содержит краткое описание мыслительных операций и их участие в становлении количественного и качественного объема знаний, умений и навыков студента. Даются некоторые рекомендации по формированию серии контрольных вопросов к учебному тексту, рассчитанных на тренинг определенных мыслительных операций.

Ключевые слова: учебный текст, репродуктивные действия, продуктивные действия, мыслительные операции.

просов заключается в элементе самопроверки, то есть первичного этапа контроля степени присвоения материала. Этот этап очень важен тем, что на нем происходит первичное осмысление и своего рода тренаж действий по размещению данного материала в системе личных знаний, умений, навыков. Этот аспект полезности и необходимости работы с контрольными вопросами нужно постоянно прививать студентам с самого начала их обучения.

Процесс осмысления учебного материала - мыслительный процесс, состоящий из операций мышления. Они, с одной стороны, являются составляющими акта мышления, с другой стороны происходит тренинг использования этих операций на текстах более незнакомых сложного и объемного уровня. В связи с этим, хотелось бы отметить следующее - будущий студент предполагает (во всяком случае, школьное развитие этому способствует), что к окончанию школы он владеет арсеналом операций мышления: сравнением, анализом, синтезом, абстракцией и обобщением. Именно эти операции приводит психолог С.П. Рубинштейн [3] в качестве основных. Так, наряду с предыдущей целью (присвоением материала) контрольные вопросы позволяют определять дальнейшее развитие и использование операций мышления в более сложных текстах, с которыми оперирует университетское образование.

Коротко представим признаки этих операции. Каждую операцию обозначим буквой для дальнейшего из- 
ложения материала.

Сравнение (C) - сопоставляет вещи, явления, их свойства, вскрывает тождество и отличия.

Анализ (А) - мысленно расчленяет предмет, явление, ситуацию и выявляет составляющие его элементы, части, моменты, стороны.

Синтез (Сз) - восстанавливает расчленяемое анализом целое, вскрывая существенные связи и отношения.

Абстракция (Аб) - это выделение, вычленение и извлечение одной какой-нибудь стороны, свойства, момента явления или предмета в каком-нибудь отношении существенного и отвлечение от остальных.

Обобщение, или генерализация, (О) - это нахождение общего в предметах и явлениях, причем нахождение общего включает в себя сопоставление предметов, вычленение общих признаков в каждом из данных предметов и объединение последних по этим признакам.

В последнее время в число операций мышления включают:
1. конкретизацию - выявление определенного предмета, детали, качества, свойства или явления, это уточнение необходимое для наиболее полного раскрытия его содержания;

2. систематизацию (классификацию) - мысленное распределение предметов или явлений по группам или подгруппам в зависимости от сходства и различий (деление категорий по существенному признаку) [4].

Эти две последние операции представляются нам несколько искусственными, так как они являются проявлением операции обобщения, генерализации не отдельного предмета, а класса предметов или явлений.

Если рассуждать о контрольных вопросах, то каждый из них отражает узкую задачу и, как правило, в мыслительном процессе опирается на одну или две преобладающие мыслительные операции. Анализ часто встречающихся контрольных вопросов позволил выявить некоторые характерные особенности, отраженные в сводной таблице.

Таблица содержит начальные слова или фразы контрольных вопросов, которые формулируются в виде во-

Таблица 1.

Возможные варианты контрольных вопросов и их направленность

\begin{tabular}{|c|c|c|c|c|}
\hline № $п / п$ & Вопрос & Характер & Операции & Пример \\
\hline 1 & Где (в каком случае) ...? & РД & $A, C$ & Где применяют двигатели постоянного тока? \\
\hline 2 & Для чего ...? & РД & $A, 0$ & Для каких целей используют асинхронный двигатель? \\
\hline 3 & Что (кто)...? & РД & A, A6 & Что такое интеллектуальный датчик? \\
\hline 4 & Сколько ...? & РД & $\mathrm{A}, \mathrm{C}$ & Сколько форм имеет процесс мышления, определите их? \\
\hline 5 & Почему...? & РД & $A, 0$ & $\begin{array}{l}\text { Почему в качестве сердечника используют трансформаторную } \\
\text { сталь? }\end{array}$ \\
\hline 6 & Каков (какова) ... ? & РД & $\mathrm{A6}, \mathrm{C}_{3}$ & Каковы условные графические обозначения датчиков? \\
\hline 7 & Какой (какая, какие)? & РД & $A 6,0$ & $\begin{array}{l}\text { Какое физическое явление лежит в основе пьезоэлектрическо- } \\
\text { го датчика? }\end{array}$ \\
\hline 8 & Установите (найдите) соответствие... & ПД & $\mathrm{C}, \mathrm{A}$ & Найдите соответствие между указанными явлениями... \\
\hline 9 & Определите ... & ПД & $\mathrm{A} 6, \mathrm{C}_{3}$ & $\begin{array}{l}\text { Определите (по схеме), где происходит утечка воздуха в } \\
\text { ситуации... }\end{array}$ \\
\hline 10 & Объясните ... & ПД & $\mathrm{A} 6, \mathrm{C}_{3}$ & 0бъясните действие контргруза \\
\hline 11 & Найдите ... & Пд & $\mathrm{C} 3, \mathrm{~A} 6$ & Найдите сходство между приведенными предметами. . . \\
\hline 12 & Выберите ... & ПД & $C, 0$ & Выберите из списка определенные предметы. . . \\
\hline 13 & Что произойдет, если .. & ПД & $C_{3}, 0$ & $\begin{array}{l}\text { Что произойдет, если изменить последовательность отключе- } \\
\text { ния? }\end{array}$ \\
\hline 14 & Используется ли в практике... . & ПД & $A, 0$ & Используется ли на практике явление магнитострикции? \\
\hline 15 & $\begin{array}{l}\text { Выстройте в порядке (проранжи- } \\
\text { руйте) ... }\end{array}$ & ПД & $\mathrm{C}, \mathrm{A} 6, \mathrm{C} 3$. & $\begin{array}{l}\text { Проранжируйте в порядке значимости при обработке давлени- } \\
\text { ем приведенные свойства стали. }\end{array}$ \\
\hline 16 & Укажите ... & ПД & $A, 0$. & $\begin{array}{l}\text { Укажите последовательность операций и процессов при пуске } \\
\text { электрического генератора. }\end{array}$ \\
\hline
\end{tabular}


просительного или повествовательного предложения, характер ответа (репродуктивный (РД), продуктивный (ПД)) и пример конкретного контрольного вопроса или его смысловой существенной части.

Из таблицы следует, что репродуктивные действия основаны, в основном, на операции анализа, тогда как продуктивные действия требуют операции синтеза. Ответ, если он не сумбурный или построенный на хорошей «фотографической» памяти, как правило, требует операции обобщения.

Все приведенные в таблице вопросы в вопросительной или повествовательной форме не являются обязательными, кроме того, в различных контекстах они могут иметь и другой смысл и быть рассчитаны на другую преимущественную операцию.

Как говорилось выше, при чтении теста в мыслительном процессе участвуют все операции, однако по харак- теру и роли вопроса он может опираться на преимущественную операцию. Сам вопрос также проходит через все операции мышления. Однако заметим, что необходимо разнообразить виды вопросов, так как это более способствует тренировке и равномерному использованию всех операций.

Психологи утверждают, что все мыслительные операции (действия) протекают не изолированно, а в различных сочетаниях (это отражается и в таблице). Кроме того, у разных людей отдельные виды мыслительных операций развиты больше, например, преобладает анализ. Поэтому и важно развивать весь комплекс.

Таким образом, контрольные вопросы наряду с другими мероприятиями текущей аттестации выполняют задачу развития и оттачивания мыслительных операций, что является важным как для дальнейшего обучения, так и для развития студентов как профессионально мыслящих индивидуумов.

\section{ЛИТЕРАТУРА}

1. Пашина, Е.В. Вопросы к тексту как стратегия смыслового чтения / Е.В. Пашина. // Инновационные педагогические технологии: материалы IV Междунар. науч. конф. (г. Казань, май 2016 г.). - Казань: Бук, 2016. - С. 11-15. - URL: https://moluch.ru/conf/ped/archive/190/10361/

2. Как составить контрольные вопросы. - URL: https://www.omgtu.ru /general_information/departments/publishers/the-design-of-the-printed-publication/ how-to-write-test-questions/

3. Рубинштейн, С.Л. Основы общей психологии / С.Л. Рубинштейн. - СПб.: ПИТЕР, 1998. - 688 с.

4. Мышление. Воображение. Речь. - URL: https://monographies.ru/en/book/section?id =3152 